\title{
Bobath Concept Structural Framework (BCSF): Positioning Partial Aspects Within a Holistic Therapeutic Concept
}

\author{
Gabriele Eckhardt ${ }^{1,}$, , Kim Brock ${ }^{2}$, Gerlinde Haase ${ }^{1}$, Carmen Puschnerus ${ }^{3}$, \\ Anke Hengelmolen-Greb ${ }^{4}$, Cristian Böhm ${ }^{5}$ \\ ${ }^{1}$ Rehabilitation Unit, Center of Physiotherapy and Rehabilitation, Haan, Germany \\ ${ }^{2}$ Rehabilitation Unit, St Vincent's Health, Melbourne, Australia \\ ${ }^{3}$ Outpatient Therapy Center, Paderborn, Germany \\ ${ }^{4}$ Neurorehabilitation Hospital, Bad Camberg, Germany \\ ${ }^{5}$ Neurorehabilitation Unit, Schoen Clinic, Bad Staffelstein, Germany \\ Email address: \\ g.eckhardt@physiohaan.de (G. Eckhardt),Kim.Brock@svha.org.au (K. Brock), gerhaase@physiohaan.de (G. Haase), \\ physio@puschnerus.de (C. Puschnerus), anke.greb@gmx.com (A. Hengelmolen-Greb), physioboehm@live.com (C. Böhm) \\ ${ }^{*}$ Corresponding author
}

\section{To cite this article:}

Gabriele Eckhardt, Kim Brock, Gerlinde Haase, Carmen Puschnerus, Anke Hengelmolen-Greb, Cristian Böhm. Bobath Concept Structural Framework (BCSF): Positioning Partial Aspects Within a Holistic Therapeutic Concept. American Journal of Health Research. Vol. 6, No. 4, 2018, pp. 79-85. doi: 10.11648/j.ajhr.20180604.11

Received: July 22, 2018; Accepted: August 2, 2018; Published: September 1, 2018

\begin{abstract}
Background: The Bobath concept is a complex, holistic approach to neurorehabilitation. This complexity presents difficulties for describing Bobath therapy in a comprehensible way. The purpose of this project was to develop an external structure to promote a better understanding of how specific therapeutic procedures are categorized, how partial aspects can be organized and how their interactions can be made more obvious. Method: A scoping review of the literature was undertaken and clustered for keywords. These data were assigned to four levels of a framework model: Conceptual level (leading thoughts), Principle level (essential characteristics of the system), Method level (systematic procedures) and Technique level (the execution tools). Drafts of the framework were presented at annual conferences of the International Bobath Instructor Training Association (IBITA). Feedback from members was sought informally and in questionnaires. Results: The BCSF was supported by $75 \%$ of IBITA members $(\mathrm{N}=107)$. In the Conceptual level, three aspects were established; propositional knowledge, individual client context and professional practice knowledge. Seven components are represented in the Principle level; optimizing activity and participation, problem solving, interactive - dialogue approach, client goal oriented, identification of potential, ongoing interplay of assessment and intervention and 24 hours approach. In the Methods level, three systematic procedures were identified; activation, shaping and repetition. At the Techniques level, four execution tools were described; communication, facilitation, assignment of task and environmental arrangement. Discussion: The BCSF provides a structure for further research into the Bobath concept. At a qualitative level, this structure will allow different aspects to be explored whilst still viewing a single aspect as a component of the whole. At a quantitative level, the BCSF clarifies what kind of therapy constitutes a Bobath intervention and the factors that need to be present at all levels of the framework. Conclusion: The BCSF is a useful tool where partial aspects of the Bobath concept can be categorized into a comprehensive classification system. This classification makes it possible to focus on specific items without losing the "big picture" and to identify partial aspects and their interactions more clearly. Specific procedures can be presented in a structured and transparent manner and well documented core elements for rehabilitation of people with CNS disorders can be demonstrated.
\end{abstract}

Keywords: Bobath Concept, Conceptual Framework, Theoretical and Practical Assumptions, Structural Framework 


\section{Introduction}

The complexity of rehabilitation interventions is widely acknowledged in rehabilitation literature, described in terms such as the "black box" of therapy [1] and the "controlled chaos" of rehabilitation interventions [2]. An important direction in unpacking the "black box" is identifying the components within treatment sessions, determining the ingredients for each component, and how they are hypothesized to make a difference in a particular aspect of a patient's functioning [2]. The Rehabilitation Taxonomy of Tasks - RTT [ibid] is an example of a conceptual framework for understanding rehabilitation interventions by classifying the type of target (e.g. structural tissue properties, skilled performance), the ingredients of interventions, and the hypothesized mechanisms of action. However, the developers of the RTT acknowledge that this structure does not reveal the clinical reasoning behind the decision to choose one component or ingredient over another [3]. Understanding the clinical reasoning is necessary to explicate the tailoring of interventions for one person compared to another. The need for both detailed description of the different components of interventions and the tailoring of interventions to individual participants is essential for research into rehabilitation [4].

Neurological disorders affect up to 1 billion people worldwide, with stroke contributing more than half the burden in disabilities-adjusted life-years (DALYs) [5]. This requires specialized rehabilitation services for comprehensive management, especially treatments tapping into brain recovery through neuroplastic processes [6]. In the Western world, the Bobath concept is the most popular treatment approach used in neurorehabilitation [7]. In clinical practice in the Bobath concept, there are observable treatment components such as choice of task and environment, the use of manual facilitation and/or verbal interaction [8]. Behind these observable features are clinical decisions as to why this particular component is relevant, and hypothesized theories as to why the activity might be beneficial to the recipient. Mere descriptions of the observed phenomena do not elicit these features.

A recent review of the Bobath concept identified a body of literature addressing theoretical concepts within the Bobath concept [9]. The scoping review revealed a lack of descriptions of interventions based on the Bobath concept [10]. The paucity of published descriptions of interventions may partly stem from clinicians' concerns that the Bobath concept should be viewed as a holistic approach, rather than a series of exercises or techniques for specific clinical features. In response to this concern, it was identified that developing a clinical framework for the Bobath concept may assist in the description and interpretation of interventions based on the Bobath concept and help explicate the clinical reasoning for treatment choices for individual patients.

A therapeutic concept, such as the Bobath concept, is complex by nature and includes many-faceted partial aspects, most of which are interacting with each other. Thus, information on partial aspects, their influences and interactions is a prerequisite for understanding the big picture. An external structure can be used to promote a better understanding of how specific therapeutic procedures are categorized, how partial aspects can be organized and how their interactions can be made more obvious [11]. A methodology for describing complex models of practice has been described by Scheel [11] and utilised in developmental neurology [12-13]. Already in the early days of the concept, (1940's), the need for scientific explanation for the empirically developed treatment approach was seen by Berta and Karel Bobath. They used "headings" or "titles" to structure their representation of the Bobath concept [14]. They differentiated concept and action-oriented methods [15] and taught techniques and guiding principles [16-19].

A clinical framework for developmental neurology (pediatrics) has been published 2008 by Ritter \& Welling [12] and Viebrock \& Forst [13] to focus the relationships between aspects of therapy. This framework illustrates the flexible transitions between the therapist's thinking and decision-making and the therapeutic consequence resulting from these processes. The classification is not supposed to represent a hierarchic structure but a description of entities within a complex dynamic system. Expanding on this work, this paper presents a new structure for understanding the Bobath concept, the Bobath concept structural framework (BCSF) and the processes involved in development of the framework.

\section{Development of the Framework}

Members of two Bobath associations, Vereinigung der Bobath Therapeuten e.V. (VBT), Verein der Bobath InstruktorInnen Deutschland and Österreich e.V. (VeBID) decided to work collaboratively to develop a clinical framework for the Bobath concept. Development of the framework was through an iterative and interactive process. In the first step, the literature on the Bobath concept published in the last 55 years (1955-2010) was sifted and clustered by keywords. Literature included published articles, textbooks, training materials, interviews and video footage (can be viewed online www.vebid.de). The data obtained were discussed and reflected upon by an expert group of three representatives from VBT and assigned to the four levels of the framework. The results of the first stage of the process were published in 2010 by Viebrock et al. [20] under the title „Complex and Specific - the Bobath concept".

In the second stage (2010-2011), 52 members of VeBID, all of whom were Bobath instructors or trainee instructors, participated in working groups to further develop different aspects of the framework and trial them in clinical practice. The framework was presented at various neurological, neurorehabilitation and physiotherapy conferences in German-speaking countries.

In the third stage of development, verification of the BCSF internationally was undertaken by presenting it in theoretical 
form and with clinical examples to members of the International Bobath Instructor Training Association (IBITA) at their annual conference in Vienna (2011). Feedback was sought from the membership to gauge the acceptability of the framework and guide further development. A high level of consensus was reached, with $83.33 \%(\mathrm{~N}=96)$ of members indicating "strongly agree" or "agree" to the question: "Do you think the IBITA members should continue working on/ further developing the preliminary framework presented in Vienna?"

In a final phase, the framework was extended with further clinical examples and presented at the Annual IBITA meetings in 2012 and 2013, with the completed version presented in Florence in 2014. At this meeting in 2014, IBITA members were asked if they wanted to use the framework in future with $75 \%(\mathrm{~N}=107)$ indicating "agree" or "strongly agree" (see figure 1).
Percentage of persons wanting to use the MBCF in future

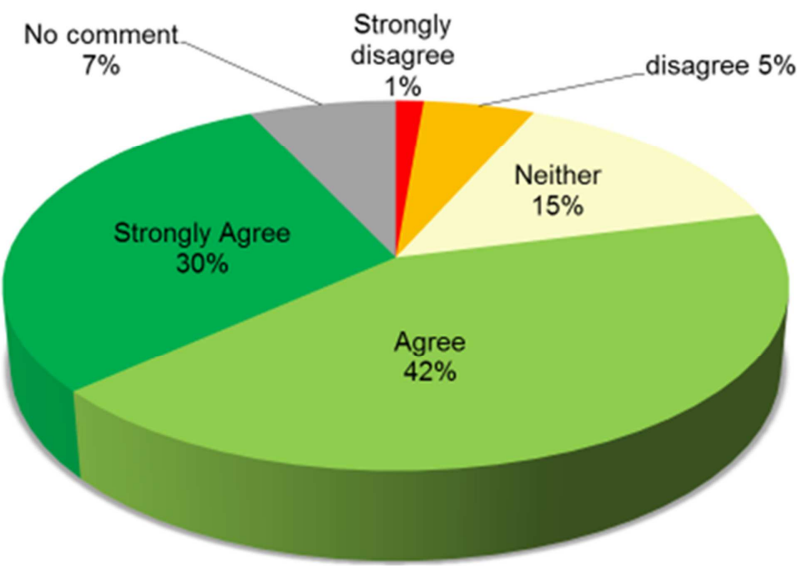

Figure 1. IBITA MEMBERS (N=107) Agreement BCSF AGM 2014.

Table 1 shows levels of agreement regarding the situations they would find the Framework useful.

Table 1. IBITA questionnaire 2014: in which situations do you find the BCSF useful?

\begin{tabular}{|c|c|c|c|c|c|c|}
\hline $\mathrm{N}=107$ & strongly disagree & disagree & neither agree nor agree & agree & strongly agree & no comment \\
\hline Exchange with physicians & 1 & 13 & 24 & 39 & 24 & 5 \\
\hline As a tutor for a patient demonstration & 0 & 3 & 10 & 53 & 33 & 7 \\
\hline As a tutor in a candidate module & 0 & 2 & 14 & 49 & 29 & 12 \\
\hline As a staff member to transfer information & 3 & 7 & 17 & 36 & 34 & 7 \\
\hline
\end{tabular}

\section{Structure and Content of the Bobath Concept}

The BCSF describes processes of decentralized decisionmaking within related heterarchical structures. This requires that interacting partial aspects in non-deterministic systems have the ability and the opportunity to take decisions autonomously [11]. The framework consists of four levels. The conceptual level can be understood as leading thoughts, the principles are a guide for action, the methodological level provides systematic procedures, and the technical level presents therapeutic means. The components of each of these strata are listed in figure 2.

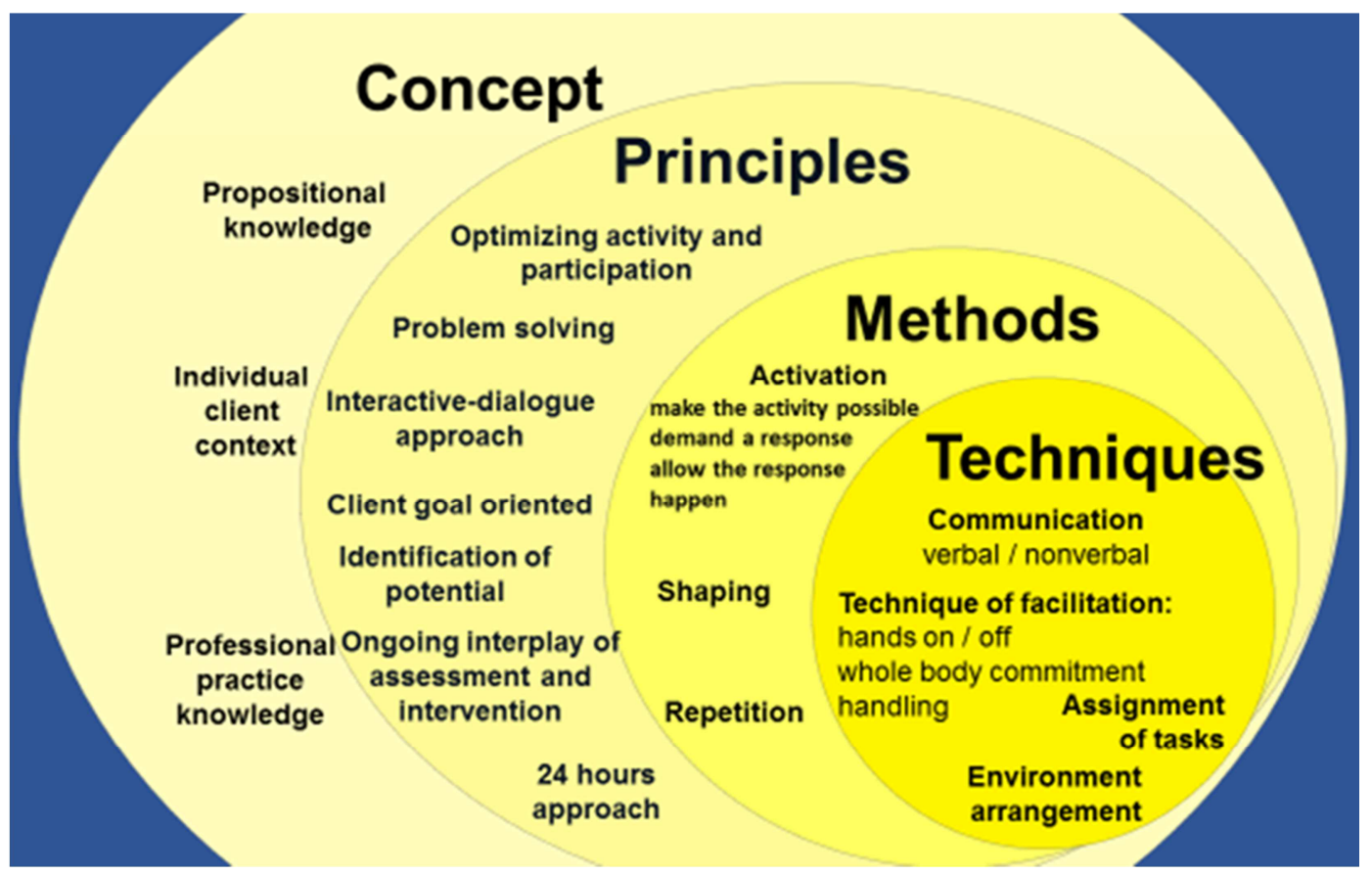

Figure 2. Bobath Concept Structural Framework (BCSF 2017). 


\subsection{Concept Level}

The concept level has three components: propositional knowledge, individual client context and professional practical knowledge. Propositional knowledge includes knowledge of motor control, motor learning, neuromuscular plasticity, human movement behaviour, neurological dysfunction and evidence-based medicine [21-23]. The structure of the biopsychosocial model corresponds with the individual client context, characterized by respect for the autonomy and dignity of the person in accordance with ICF guidelines [8]. Thus, the person is holistically involved in the individual learning process [21, 24]. Professional practical knowledge is the sum of all empirical knowledge the experienced therapist has acquired over the years [25-26] This includes knowledge gained by participating in postgraduate Bobath training courses at beginner and advanced levels. These courses impart both explicit knowledge and procedural (implicit) knowledge in assessment, clinical reasoning and treatment skills [27-29]. The therapist learns to select and apply individual therapeutic interventions to individual patients within their personal and environmental context $[12,30]$.

\subsection{Principle Level}

Principles are essential characteristics of the system that guide interventions and provide the basis for assuring that therapy is an active learning process for the patient [14]. The principle level (superordinate ideas) has seven components (figure 2).

The BCSF acknowledges the primacy of the ICF framework with the focus on optimizing activity and participation as a key principle in the Bobath concept [8]. Related to this is the requirement for interventions to be oriented towards the goals of the client. The Bobath concept has been defined as a problem-solving approach [21], based on analysis of movement behavior, in relation to personal and contextual factors $[28,31,32]$.

A key feature of assessment is the identification of potential; the potential for improvement within the person's movement abilities [28]. The ongoing interplay of assessment and treatment was recognized by Berta Bobath early in the development of the concept. "Assessment- and treatment should not be seen as separate entities, they go hand in hand" [14, p 4].

The interactive-dialogue approach in the Bobath concept places special emphasis on the learning of motor actions in context $[14,24]$. It highlights the importance of the communication between the client and therapist, both verbal and nonverbal, and focuses on key aspects such as perceiving movement and changes in movement and reflecting and adapting movement to achieve better movement outcomes [24].

The 24 hours approach supports the transfer of what has been learned into the daily routine [33-34]. It integrates the person, their relatives, all professions involved, the person's self-training [34], adjustment of the environment and application of appropriate aids [35] and is applicable in all phases of rehabilitation [27].

\subsection{Method Level}

The method level is focused on systematic procedures that are action oriented to fulfill the principles. This level specifies how the therapist approaches the tasks. The first component is "activation" which address neuromuscular, biomechanical, sensory, perceptive, cognitive and emotional systems as well as task oriented activities. Activation can be represented by a statement by Berta Bobath, "make the activity possible, demand a response, allow the movement to happen" $[14,36]$. The primary intention of therapy is to activate the person to control the body in the gravitational force field in an action-related manner [36-37]. Making an activity possible might require interventions at an impairment level to optimize neuromuscular activity and biomechanical relationships [32]. Choice of the task and context may make it necessary for the person to utilize more optimal movement strategies. At this point, the therapist allows the movement to happen (evolve) under the control of the person [32].

The term 'shaping' is defined as approaching a desired motor or behavioral objective in small steps by successive approximations, with a focus on enhancing the likelihood of success in performing movements that are relevant to everyday life [38]. Berta Bobath described a similar process [14], matching the task requirement closely to where the person is in his ability level. The method of shaping includes a strong focus on achieving improvement in performance, both quantitative and qualitative, both within single sessions and within the rehabilitation process [39]. In the Bobath concept, continuous assessment of the person's response is central to interventions [28].

"Repetition" of movements is necessary for skill acquisition and motor learning. However, the repetition of a "wrong" movement behavior (eg. use of stereotypical compensation strategies) may help the patient to reach his goal (eg. standing up) but may then hinder stability and movement efficiency in other, more sophisticated functions (e.g. activities requiring balance in standing) [40]. In Bobath repetitions are usually performed with variations - learn to repeat without repeating [23, 41]. The goal is not training compensation strategies but a resource- and target-oriented, richly varied and controlled movement spectrum to be used in everyday life [35, 39].

The methods are always in relation to the above-mentioned principles and not solely directed at a pre-defined goal but specifically address the patient's learning potential [13].

\subsection{Technique Level}

The technique level of the Bobath concept represents the execution tools, the contents of the 'toolbox' used by therapists to effect interventions. Four components are included (figure 2). 
Facilitation was defined by Bertha Bobath as "making easy"; the therapist's facilitation results in the movement feeling easier for the patient because the patient's own activity is recruited [32]. For better understanding three aspects of facilitation are highlighted in the BCSF; "hands on", "hands off" and "whole body commitment".

The "hands on" technical component involves the use of sensory inputs in the form of tactile and proprioceptive information from the hands to shape movement [14, 22]. By guiding the person's sensory experiences during task performance, the therapist aims to re-educate the person's own internal referencing system $[8,21]$. The "hands on" component is not passive $[8,32]$ and must be an active learning process on the part of the person being facilitated [32]. The therapist also uses their hands to perceive information both before and during "hands on" inputs, as the person responds [42]. In this way, the treatment is a constant interaction between the patient and the therapist $[14,24]$.

"Hands on" techniques are used for direct contact with the patient only when and as long as it is necessary [43]. The goal of each "hands on" technique is to make the patient independent from the therapist's hands. „,...it is the art of knowing when to remove the hands..." $[14,43]$. "Hands on"and "hands off" techniques can alternate very quickly - even within a single motion sequence [20]. "Hands off" techniques include the use of verbal input, gesture and demonstration and can be used to direct or restrict a motion sequence, to demand or take away attention, to promote independence and self exploration and for motivation and reinforcement [14, 20]. As a result, the patient learns how the movement feels and that he can actively control it [14, 34].

Therapeutic handling involves more than use of the hands alone, it can involve "whole body commitment". The therapist's own body movements during facilitation give the person the feeling and idea of the requested movement, and invite the patient to imitate and explore activities and experiment with them [20, 32, 34].

"Communication" means the exchange of information used purposefully as a technical option in the context of therapy $[11,24]$. The way the therapist verbally and non-verbally interacts with the patient, can be inviting, motivating, soothing, activating, moderating or questioning. Phrases can be complex or simple, adjusted to the context, the way of thinking or the cognitive capacity of the patient. Communication promotes the idea of a movement, creates associations, provides clear guidelines, initiates, accelerates, slows or stops an action, guides the attention or distracts the patient from a task. If the therapy is focusing on other somatosensory processes, language may be purposefully excluded [44].

"Environment arrangement" is the adjustment or (re) structuring of the environment, referring to the selection of the immediate and surrounding environmental context, the starting position, the support surface, the alignment of the body in the gravitational force field, and the materials and objects used [20-21, 35]. The structure of the environment is a key factor in the "activation" component whereby the therapist makes a movement easier or possible or necessary for the patient. Environment adjustments are also used to enable the therapist to reduce or remove the requirement to use "hands on" $[14,20]$. On the basis of the patient's specific disabilities the therapist selects the environment to invite the patient to learn, including "real life" contexts [20].

"Adjustment of the task" includes both simple and complex motor actions and functional activities requiring problem solving [ibid]. Selection of task is based on hypotheses concerning the potential cause of the patient's change in behavior, the knowledge of biomechanics, the influence of gravity on postural systems and the cognitive involvement in motor actions. Task related therapy also includes use of mental imagery and observation or imitation of movements in the processes of motor learning [45-46]. Specific aspects of the technical level should not be regarded as a succession of exercises or patterns to be used in the order given; techniques are tools and are therefore interchangeable.

\section{Discussion}

This paper presents the development of an external structure, the BCSF, to promote a better understanding of the Bobath concept, facilitate description of specific components of the Bobath concept and support research into interventions based on the Bobath concept. In an interative process over a five years timeframe, each aspect of the BCSF has been described and analyzed without losing the whole picture.

The BCSF demonstrates that the Bobath concept is a kind of thinking in which the Bobath therapist uses specific techniques, based on overarching ideas and professional practice knowledge (concept) with regard to guiding principles, in a systematic way (method). The therapist's clinical reasoning is guided by the precepts of the concept. Theoretical knowledge (reference theories), the idea of man (individual client context), practical knowledge and principles, methods and techniques are brought into a continuous interaction with each other and with the environment in which they are taking place. The BCSF ensures that the Bobath concept is viewed in a holistic way. When describing interventions based on the Bobath concept, consideration needs to be given to all levels of the BCSF, not limited to the more readily observable technical level. The BCSF can be utilized in many circumstances; scientific research, conference presentations, case studies, training/education of instructors, exchange with colleagues, and the teaching of the Bobath concept to participants at introductory, basic and advanced courses.

The outcome of the BCSF indicates there are no specific "Bobath techniques" or specific "Bobath training programs" that can be learnt or investigated in isolation. Most commonly, movement exercises, manual therapy skills, use of machines etc. are part of the basic training and education of therapists. Use of the Bobath concept requires a holistic 
approach, where the decisions of an experienced Bobath therapist emerge from consideration of the whole BCSF, oriented towards the patient's abilities and situation, identifying which step should (or can) be learned next and which therapeutic means provides the best support for the person at this moment in time.

The BCSF provides a structure for further research into the Bobath concept. At a qualitative level, this structure will allow different aspects to be explored whilst still viewing a single aspect as a component of the whole. At a quantitative level, the BCSF clarifies what kind of therapy constitutes a Bobath intervention and the factors that need to be present at all levels of the framework. There is potential for the framework to be used when looking at the 'ingredients' of an intervention as proposed by Hart et al. [2], to further understand the clinical reasoning behind the choice of 'ingredients' and to explicate the tailoring of interventions to individuals, as discussed by Boutron [4]. The many faceted nature of the Bobath concept is a challenge for research; the BCSF encourages researchers to consider the complexity of the treatment approach being investigated.

Limitations of this study include lack of use of a formal qualitative methodology. However, the more informal methodology of the study maximized the opportunities for Bobath experts to contribute to and review the developing framework over a prolonged period of time.

\section{Conclusion}

With the BCSF, partial aspects of the Bobath concept can be categorized in a comprehensive classification system. This classification makes it possible to focus on specific items without losing the "big picture" and to identify partial aspects and their interactions more clearly. Specific procedures can be presented in a structured and transparent manner and well documented core elements for rehabilitation of people with CNS disorders can be demonstrated. Further research is needed to describe and investigate each partial aspect of the BCSF.

\section{Acknowledgements}

A big "thank you" to all IBITA colleagues who are involved in the development of BCSF. A very special thank you and compared with great respect go to Karin Cornelius and Helga Treml-Sieder, both responsible for the Bobath archive, under the direction of VBT. Without their tremendous work, original Bobath literature would disappear for future generations. Thank you Hille Viebrock, Christa Grafmüller-Hell, Gisela Ritter, Barbara Forst and Alfons Welling for your excellent work on behalf of the Bobath Concept.

\section{Conflict of Interest}

All the authors do not have any possible conflicts of interest.

\section{References}

[1] Bode, R., Heinemann, A., Semik, P., \& Mallison, T. (2004). Patterns of therapy activities across length of stay and impairment levels: peering inside the "black box" of inpatient stroke rehabilitation. Arch Phys Med Rehabil, 1901-8.

[2] Hart, T., Tsaousides, T., \& Zanca, J. (2014). Toward a theorydriven classification of rehabilitation treatments. Arch Phys Med Rehabil. 33-S44.

[3] Dijkers, M. (2014). Rehabilitation treatment taxonomy: establishing common ground. Arch Phys Med Rehabil. 1-S5.

[4] Boutron, I., Moher, D., Altman, D., Schulz, K., \& Ravaud, P. (2008). Extending the CONSORT Statement to Randomized Trials of Nonpharmacologic Treatment: Explanation and Elaboration. Ann Intern Med., 295-309.

[5] Chin, J., \& Vora, N. (2014). The global burden of neurologic diseases. Acad. of Neurology, 349-351.

[6] Khan, F., Amatya, B., Galea, M., Gonzenbach, R., \& Kesselring, J. (Oct 2016). Neurorehabilitation: applied neuroplasticity. J Neurol, DOI 10.1007/s00415-016-8307-9.

[7] Kollen, B., Lennon, S., Lyons, B., Wheatley-Smith, L., Scheper, M., Buurke, J. Kwakkel, G. (2009). The Effectiveness of the Bobath concept in Stroke Rehabilitation. What is the Evidence? Stroke (02:24).

[8] Vaughan-Graham, J., Eustache, C., Brock, K., Swain, E., \& Irwin-Carruthers, S. (Jan-Febr. 2009). The Bobath concept in contemporary clinical pracitice, Review. Top Stroke rehab., S. 16 (1) $57-68$.

[9] Vaughan-Graham, J., Cott, C., \& Wright, V. (2014). The Bobath (NDT) concept in adult neurological rehabilitation: what is the state of the knowledge? A scoping review Part I: conceptual perspectives. Disab Rehabil.

[10] Vaughan-Graham, J., Cott, C., \& Wright, V. (2014). The Bobath (NDT) concept in adult neurological rehabilitation: what is the state of the knowledge? A scoping review Part II: intervention studies perspectives. Disabil Rehabil.

[11] Scheel, K. (2013). Modelle und Praxiskonzepte der Physiotherapie, Eine Verortung innerhalb von Anthropologie und Ethik. Bd. 6, ISBN 978-3-643-12040-3: Reihe: Pädagogik - Sport Kultur - Philosophie.

[12] Ritter. G, \& Welling, A. (2008). Die zehn Prinzipien des Bobath Konzeptes in der Kindertherapie. Stuttgart: Thieme Verlag.

[13] Viebrock, H., \& Forst, B. (2008). Therapiekonzepte in der Physiotherapie. Stuttgart: Thieme Verlag.

[14] Bobath, B. (1977). Treatment of Adult Hemiplegia. Physiotherapy, 53 (10):310-313.

[15] Schönberger, F. (1984). Bobath Konzept und kooperative Pädagogik. Z. f. Krankengymnastik, S. 11:725-736.

[16] Treml-Sieder, H. (1989). Das Bobath Konzept- eine Herausforderung. Beschäftigungstherapie und Rehabilitation, 4:247-252.

[17] Ritter, G. (1998). Das Bobath Konzept- Praxiserfahrungen und Fragen an die Theorie. Bewegung und Entwicklung, 1:31-40. 
[18] Ritter, G. (2004). Einzelfallstudie zur Bobath Therapie: einige Schlussfolgerungen für die Therapiepraxis und für die Lehre im Bobath Konzept. Z. f. Krankengymnastik. 11; 2064-2081.

[19] Welling, A., Forst, B., \& Ritter, G. (2006). Niklas und die Bobath Therapie, Dokumentation einer Einzelfallstudie. Stuttgart: Thieme.

[20] Viebrock, H., Eckhardt, G., \& Grafmüller-Hell, C. (2010). Komplex und spezifisch- das Bobath Konzept. Bewegung und Entwicklung, Castrop-Rauxel. 978-3-643-12040-3.

[21] Raine, S. (2007). The current theoretical assumptions of the Bobath concept as determined by the members of BBTA. Physiotherapy Theory \& Practice 23:137-52.

[22] Levin, M., \& Panturin, E. $\uparrow$ (2011). Sensory motor integration for functional recovery and the Bobath concept. Motor Control, S. 15:285-301.

[23] Raine, S., Meadows, L., \& Lynch-Ellerington, M. (2009). Bobath concept: Theory and Clinical Practice in Neurological Rehabilitation. Oxford: Wiley-Blackwell.

[24] Eckhardt, G., Haase, G., Brock, K., \& Hummelsheim, H. (2016). Interactive-dialogue in Bobath therapy: a mixed method study. International Journal of Therapy and Rehabilitation, Vol 23, No 2. 233-242.

[25] Skjaerven, L. H., Kristofferson, K., \& Gard, G. (2008). An eye for movement quality: A phenomenologicial study of movment quality reflecting a group of physiotherapists' understanding of the phenomenon. Physiotherapy Theory and Pracice, 24 (1):13-27.

[26] Holdar, U., Wallin, L., \& Heiwe, S. (2013). Why do we do as we do? Factors influencing Clinical Reasoning and Decisionmaking among physiotherapist in an acute setting. Physiother. Res. Int.

[27] Eckhardt, G., \& Greb, A. ((61) 9 2009). Bobath für Erwachsene - Konzepte stellen sich vor. pt_Zeitschrift für Physiotherapeuten, S. 1-4.

[28] Johnson, P. (2009). Assessment and Clinical Reasoning in the Bobath concept. In S. Raine, L. Meadows, \& M. LynchEllerington, Bobath concept: Theory and Clinical Practice in Neurological Rehabilitation. Oxford: Wiley-Blackwell.

[29] Hengelmolen-Greb, A. (2016). Qualitätssicherung im BobathKonzept: Überprüfung der Lerninhalte von BobathGrundkursen: Enthält der Lehrplan evidenzbasierte Maßnahmen? Physioscience, 12:17-25

[30] Ritter, G., Welling, A., \& Eckhardt, G. (2014). Die zehn Prinzipien des Bobath Konzeptes. Castrop Rauxel: Vereinigung der Bobath Therapeuten e. V.

[31] Bobath, B. (1990). Adult Hemiplegia: Evaluation and treatment. Oxford:Butterworth-Heinemann.
[32] Gjelsvik, B. (2016). The Bobath concept in adult neurology. (second edition) Stuttgart-New York: Georg Thieme Verlag.

[33] Flehming, I. (1987). (3. überarb. Auflage)). Normale Entwicklung des Säuglings und ihre Abweichungen. Früherkennung und Frühbehandlung. Stuttgart: Thieme.

[34] Bobath, B., \& Finnie, N. (1970). Problems of Communication between Parents and Staff in the Treatment and Management of Children with Cerbral Palsy. Med. and Child Neurology, 12 (5):629-635.

[35] Greb, A., \& Kiesewetter, C. (2008). Bobath Konzept für Erwachsenen. In G. Ebelt. Paprotny, \& R. Preis, Leitfaden Physiotherapie 5. Aufl. München: Urban \& Fischer.

[36] Bobath, B. (1985). Fazilitation. Unveröff. Vortrag Aufbaukurs. (1985). Berlin, Deutschland.

[37] Bobath, B. (1979). The application of physiological principles to stroke rehabilitation. The Practitioner, 223:793-794.

[38] Taub, E., Crago, J. E., Burgio, L. D., Groomes, T. E., Cook, E. W., DeLuca, S. C., \& Miller, N. E. (March 1994). An operant approach to rehabilitation medicine: overcoming learnes nonuse by shaping. Journal of the experimental analysis of behaviour, 61, 281.293.

[39] Eckhardt, G. (2013). Posturale Kontrolle und die Bedeutung für das Sturzrisiko bei Patienten: Teil 2: Das Strukturmodell in Bobath. PT-Zeitschrift, 32-36.

[40] Kitago, T. \&. Krakauer (2014). Motor learning principles for neurorehabilitation. In D. In: Barnes M. / Good, Handbook of Clinical Neurology. (93-103.). Elsevier Verlag.

[41] Lee, A. (1991). Research on teaching in physical education: questions and comments. Res Q Exerc Sport. Dec; 62 (4):3749.

[42] Selver, C. (1991). Erinnerungen an Elsa Gindler: Persönliche Mitschriften, Berichte, Briefe. Gespräche mit Schülern. Zeitschrift für Krankengymnastik. (69-79.). Pflaum Verlag, München.

[43] Bobath, B. (1985). Fazilitation. Unveröff. Vortrag Aufbaukurs. (1985). Berlin, Deutschland.

[44] Park, J., Shea, C., \& Wright, D. (2000). Reduced frequency concurrent and terminal feedback: a test of guidance hypothesis. Journal of motor behavior, 33 (3):287-296.

[45] Zimmermann-Schlatter, A. (2008). Efficacy of motor imagery in post-stroke rehabilitation: a systematic review. Journal of Neuroengineering and Rehabilitation.

[46] Barclay-Goddard Ruth, E. (2010). Mental practice for treating upper extremity. Cochrane Database of Systematic Reviews. 